\title{
Xanthohumol inhibits STAT3 activation pathway leading to growth suppression and apoptosis induction in human cholangiocarcinoma cells
}

\author{
HASAYA DOKDUANG $^{1,3}$, PUANGRAT YONGVANIT ${ }^{1,3}$, NISANA NAMWAT $^{1,3}$, \\ CHAWALIT PAIROJKUL ${ }^{2,3}$, SAKKARN SANGKHAMANON ${ }^{2,3}$, MIKA SAKURAI YAGETA $^{4}$, \\ YOSHINORI MURAKAMI $^{4}$ and WATCHARIN LOILOME ${ }^{1,3}$
}

\begin{abstract}
Departments of ${ }^{1}$ Biochemistry and ${ }^{2}$ Pathology, and ${ }^{3}$ Liver Fluke and Cholangiocarcinoma Research Center, Faculty of Medicine, Khon Kaen University, Khon Kaen 40002, Thailand; ${ }^{4}$ Division of Molecular Pathology, Department of Cancer Biology, Institute of Medical Science, the University of Tokyo, Tokyo 108-8639, Japan
\end{abstract}

Received October 19, 2015; Accepted November 24, 2015

DOI: $10.3892 /$ or.2016.4584

\begin{abstract}
STAT3 plays a significant role in the development of cholangiocarcinoma (CCA) associated with the liver fluke (Opisthorchis viverrini; Ov). Xanthohumol (XN), a prenylated flavonoid extracted from hops, has known anticancer activity and could potentially target STAT3. The present study determined the effect of XN on STAT3, as well as ascertained its usefulness against CCA. The CCA cell proliferation at $20 \mu \mathrm{M}$ and $50 \mu \mathrm{M}$ of $\mathrm{XN}$ was shown to inhibited, while $20 \mu \mathrm{M}$ partially inhibited IL-6-induced STAT3 activation. At $50 \mu \mathrm{M}$, the inhibition was complete. The reduction in STAT3 activity at 20 and $50 \mu \mathrm{M}$ was associated with a significant reduction of CCA cell growth and apoptosis. We also found that the administration of $50 \mu \mathrm{M} \mathrm{XN}$ orally in drinking water to nude mice inoculated with CCA led to a reduction in tumor growth in comparison with controls. In addition, apoptosis of cancer cells increased although there was no visible toxicity. The present study shows that XN can inhibit STAT3 activation both in vivo and in vitro due to suppression of the Akt-NFkB signaling pathway. $\mathrm{XN}$ should be considered as a possible therapeutic agent against CCA.
\end{abstract}

\section{Introduction}

Cholangiocarcinoma (CCA) or bile duct epithelial cancer associated with the liver fluke (Opisthorchis viverrini; $\mathrm{Ov}$ ) infection is the most common cancer in northeast Thailand (1-3). CCA is a slow progression cancer with no specific symptoms and most CCA patients usually present

Correspondence to: Dr Watcharin Loilome, Department of Biochemistry, Faculty of Medicine, Khon Kaen University, Khon Kaen 40002, Thailand

E-mail:watloi@yahoo.com

Key words: cholangiocarcinoma, STAT3, xanthohumol with the advanced incurable stage. Surgical restriction is the best treatment regimen for CCA $(4,5)$. However, not all CCA patients are good candidates for curative surgery and complete surgical restriction is often followed by local recurrence with a less than satisfactory 5-year survival rate $(6,7)$. Therefore, the identification of putative therapeutic targets and/or potential anticancer agents against this malignancy is urgently needed.

A signal transducer and activator of transcription (STATs) family of protein kinases play roles in the immune response mechanism, inflammation and cellular development $(8,9)$. Conversely, abnormal activation of STATs has been shown to be involved in the genesis and progression of several types of cancers as well as CCA (10-12). We have previously reported the involvement of protein kinases in CCA development and they represent promising targets for CCA treatment $(13,14)$. Among the kinases, the STAT protein family particularly STAT3 was defined as the major STAT which played a role in inflammation that contributed to CCA carcinogenesis and progression, and was associated with poor prognosis of CCA (15). Therefore, STAT3 could be a potential molecular target for CCA prevention and treatment.

During the past decade, the strategy for cancer prevention and treatment of the identification and characterizations of dietary phytochemicals that are capable of blocking or reversing carcinogenesis as well as possessing anticancer properties has received increased research focus (16-19). Xanthohumol (XN) has been identified and suggested to possess chemopreventive and anticancer activities in every step of carcinogenesis. XN can potently inhibit pro-carcinogen activating and detoxifying enzymes as well as exhibiting antioxidant and free-radical scavenging activity (20). This compound also has an anti-inflammatory activity by abrogating the expression of several inflammatory genes, such as cyclo-oxygenase (COX-1, COX-2) and inducible nitric oxide synthase (iNOS) and it can inhibit cancer cell growth as well as tumor angiogenesis via the suppression of Akt and NFkB activation (21-24). In previous studies, the anticancer potential of $\mathrm{XN}$ has been demonstrated in several types of cancer. 
However, an inhibitory effect of XN on STAT3 and CCA development has not been reported. Therefore, the present study explored the effects of XN on STAT3 as well as CCA development in both an in vitro and a CCA xenograft model. Results obtained may assist in evaluating whether STAT3 is a potential target for $\mathrm{CCA}$ treatment and provide data regarding the effectiveness of $\mathrm{XN}$ against CCA.

\section{Materials and methods}

Cell culture. Human CCA cells, M214 and M139 were cultured and maintained as previously described (13).

Antibodies and reagents. Antibodies for western blotting were as follows: anti-phospho-STAT3 (Cambridge, UK), anti-phospho-STAT3, phospho-Akt, total Akt (Cell Signaling Technology, Danvers, MA, USA), anti-p65 NFкB (Santa Cruz Biotechology, Santa Cruz, CA, USA), anti- $\beta$ actin (Sigma-Aldrich, St. Louis, MO, USA). Recombinant human IL-6 was commercially available and purchased from R\&D Systems, Minneapolis, MN, USA. XN was kindly provided by Hopsteiner, Mainberge, Germany.

Western blot analysis. Western blot analysis was performed as previously described (15).

Cell proliferation assay. M214 and M139 CCA cells $\left(2 \times 10^{3} / 100 \mu \mathrm{l}\right)$ were seeded into 96 -well plates and incubated overnight at $37^{\circ} \mathrm{C}$ and $5 \% \mathrm{CO}_{2}$. Then, $\mathrm{XN}$ at designated concentrations was added and incubated for 24, 48 and $72 \mathrm{~h}$. Cell proliferation assay was performed using sulforhodamine B (SRB; Sigma-Aldrich, St. Louis, MO, USA) as previously described (25).

For the XN suppressed IL-6-induced STAT3 activation experiment, cell proliferation was determined by trypan blue exclusion assay. Cells were treated with $10 \mathrm{ng} / \mathrm{ml}$ recombinant human IL- 6 concomitant with the indicated concentration of $\mathrm{XN}(0,10,20$ and $50 \mu \mathrm{M})$ for $24 \mathrm{~h}$ after that cell was trypsinized and the viable cells were counted in a cell counting chamber under a light microscope. The experiment was carried out in duplicate.

Animal study. Six-week-old female BALB/cAJcl-nu/nu mice were purchased from CLEA Japan (Tokyo, Japan). Animals were housed under specific pathogen-free conditions at the animal center, Institute of Medical Science, The University of Tokyo. All animal experiments were performed according to institutional guidelines. Mice were subcutaneously injected with $2 \times 10^{6}$ cells of KKU-M214 at both flanks. One week after tumors were visible, animals were divided into two groups; the control group was provided with a vehicle $(0.5 \%$ ethanol) whereas treatment groups were administrated 20 and $50 \mu \mathrm{M}$ of $\mathrm{XN}$ in drinking water for 30 days. Drinking water solutions were secured in the amber bottles to prevent degradation and renewed on a daily basis. Mice were determined for water consumption every other day, and body weight and tumor volume were measured twice a week. The tumor volume was calculated by the formula: $0.5 \mathrm{x}$ width ${ }^{2} \mathrm{x}$ length and tumor growth was indicated by relative tumor volume (tumor volume normalized with tumor volume day 0 ).
Immunohistochemistry detection of Ki67 proliferation marker. Immunostaining of $\mathrm{Ki} 67$, proliferation marker was performed on paraffin-embedded nude mouse tumor tissues to determine the antiproliferative effect of $\mathrm{XN}$ in a CCA animal model. Nude mouse tissue sections were deparaffinized in xylene followed by rehydration in a series of different ethanol concentrations. Then, the antigen was retrieved using Tris-EDTA buffer, $\mathrm{pH} 8.8$ in pressure cooker and $0.3 \% \mathrm{H}_{2} \mathrm{O}_{2}$ was used to block endogenous peroxidase activity for $30 \mathrm{~min}$ with agitation. Nonspecific binding was blocked by $10 \%$ skim milk in phosphate-buffered saline (PBS) for $30 \mathrm{~min}$. Sections were incubated with the anti-Ki67 antibody at $4^{\circ} \mathrm{C}$ overnight in a moisture chamber.

Sections were then incubated with peroxidase-conjugated EnVision $^{\mathrm{TM}}$ secondary antibody (Dako, Denmark) followed by washing with working PBS for $5 \mathrm{~min}$, three times. After that the color was developed with $0.1 \%$ diaminobenzidine tetrahydrochloride solution for $5 \mathrm{~min}$ and followed by counterstaining with Mayer's hematoxylin. Sections were observed under a light microscope (Carl Zeiss, Germany). Ki67-positive cells of each tumor section was counted in at least five of the $\mathrm{x} 200$ power fields.

Apoptosis assay. Histologic analysis of DNA fragmentation was used to identify apoptotic cells in the paraffin sections of CCA nude mouse tissues. In situ terminal deoxynucleotide transferase-mediated dUTP nick-end labeling (TUNEL) assay was carried out using the In situ Cell Death Detection kit, POD (Roche). TUNEL-positive cells were quantified in at least five of the $\mathrm{x} 200$ power fields of randomly selected tissue sections.

Statistical analysis. Results from cell proliferation, Ki67 staining analysis, apoptosis assay and animal experiments are represented as mean $\pm \mathrm{SD}$, statistical significance was addressed by independent samples t-test and a two-way ANOVA (GraphPad Prism 5 software). P-value of $<0.05$ was considered to indicate a statistically significant result.

\section{Results}

Antiproliferative effect of XN on CCA cells. The effects of XN on the growth of CCA cells were determined in human CCA cell lines established from primary tumors of Ov-associated CCA patients namely, KKUM214 and KKU-M139. The results showed that XN inhibited CCA cell growth which occurred in a dose- and time-dependent manner. A $20 \mu \mathrm{M}$ concentration of XN significantly reduced CCA cell growth at 48 and $72 \mathrm{~h}(\mathrm{P}<0.05)$ when compared to control cells (Fig. 1A and B). Moreover, a $50 \mu \mathrm{M}$ concentration of $\mathrm{XN}$ significantly inhibited CCA cell growth at 24, 48 and $72 \mathrm{~h}(\mathrm{P}<0.05)$ in both KKU-M214 and KKU-M139 cell lines (Fig. 1A and B). Low concentrations of XN caused no evidence or significant effects on cell growth inhibition even at long exposure times.

Effects of XN on IL-6 induces STAT3 activation and CCA cell growth. We then evaluated whether inhibiting STAT3 activation leads to growth inhibition as well as apoptosis induction in CCA cells. CCA cells were exposed to XN upon stimulation with IL-6. The results showed that a low concentration of $\mathrm{XN}(10 \mu \mathrm{M})$ caused an elevation of STAT3 activation while 
A

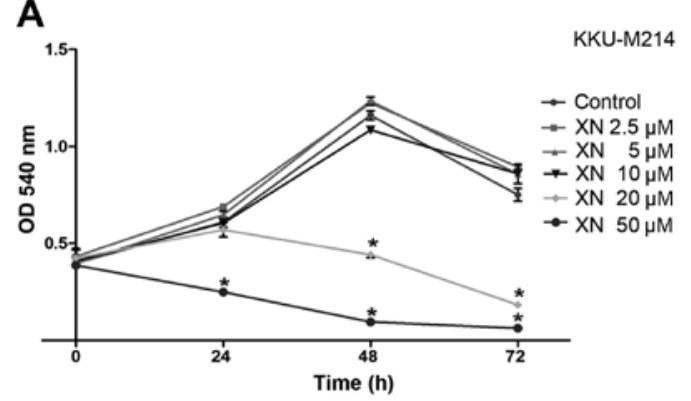

B

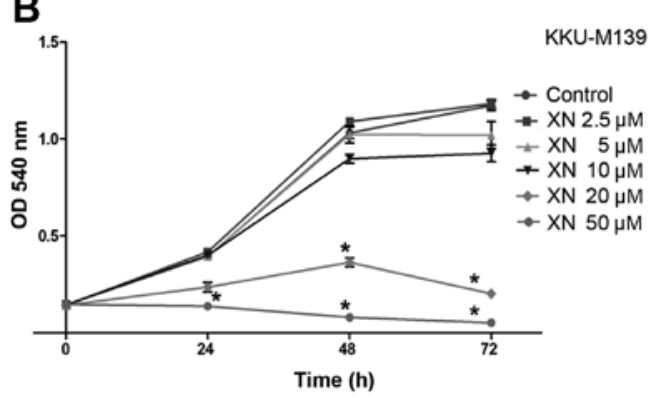

Figure 1. Growth inhibitory effect of XN on CCA cells. (A) KKU-M214 CCA and (B) KKU-M139 CCA cell lines were cultured with XN at the designated concentrations ranging from 2.5 to $50 \mu \mathrm{M}$ in $0.5 \%$ DMSO for 24,48 and $72 \mathrm{~h}$. After incubation time, cellular proteins of viable cells were measured using the sulforhodamine B assay. Values were expressed as the mean \pm SD of three individual experiments and analyzed by two-way ANOVA, ${ }^{*} \mathrm{P}<0.05$ significantly compared to control cells.

A
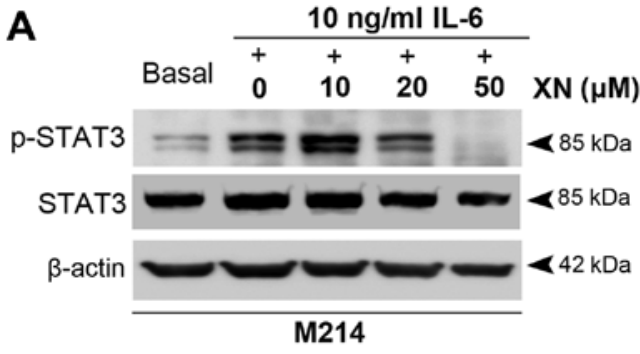

B

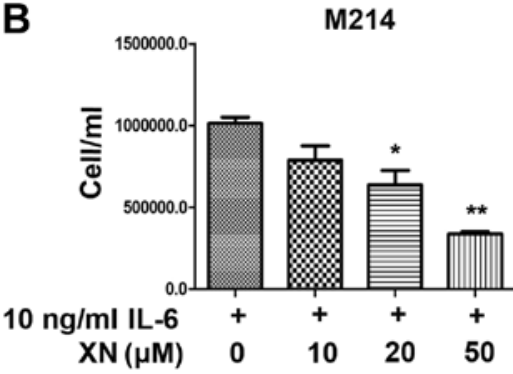

C

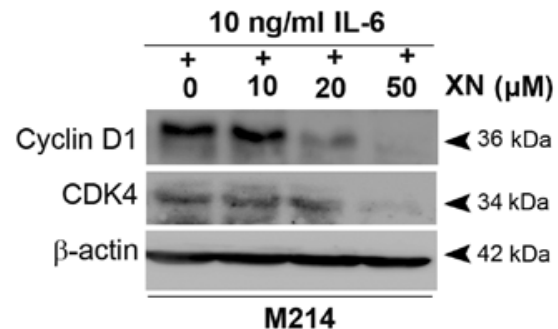

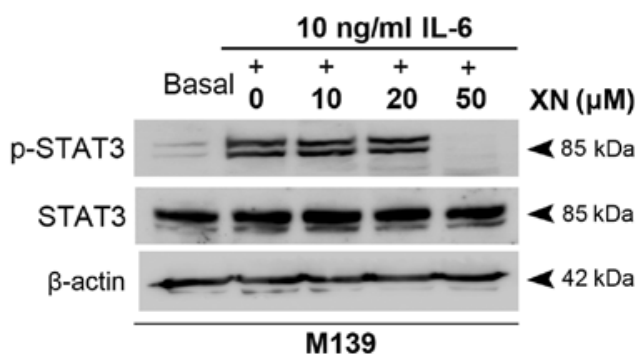

M139
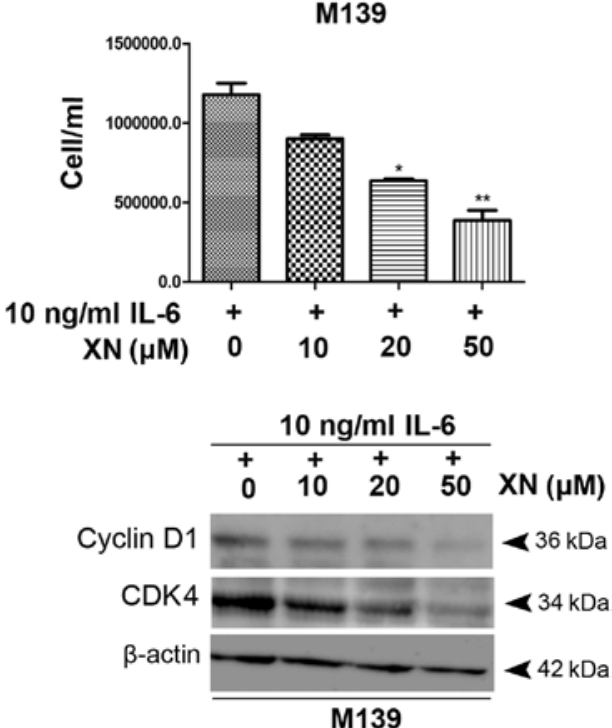

Figure 2. Inhibitory effects of XN on STAT3 activation and CCA cell growth. (A) Western blot analysis of STAT3 activation in M214 and M139 CCA cell lines after treatment with XN upon IL-6 stimulation compared to untreated control. (B) CCA cell proliferation after treatment with XN upon IL-6 stimulation was determined by trypan blue dye exclusion assay. (C) Western blot analysis of the cell cycle regulation proteins, cyclin D1 and CDK4 proteins expression. Data in (B) are mean $\pm \mathrm{SD}$ of two independent experiments and analyzed by independent samples t-test. ${ }^{*} \mathrm{P}<0.05$ and ${ }^{* *} \mathrm{P}<0.001$ compared to the control.

$\mathrm{XN}$ at $20 \mu \mathrm{M}$ concentration partially inhibited STAT3 activation. A $50 \mu \mathrm{M}$ concentration of $\mathrm{XN}$, however, completely inhibited STAT3 activity (Fig. 2A). In addition, abrogation of STAT3 activation by XN at 20 and $50 \mu \mathrm{M}$ concentrations was associated with a significant reduction of M214 and M139 CCA cell growth which was concordant with decreasing expression of cell cycle controlling proteins, cyclin D1 and CDK4 (Fig. 2B and C).

Apoptosis induction of XN in CCA cells. To investigate if suppression of STAT3 activation by XN inhibited CCA growth resulted from apoptosis induction, we examined the expression of anti-apoptosis protein, Bcl-2 as well as BAX, pro-apoptotic protein. The results demonstrated that decreasing protein levels of Bcl-2 was seen in M214 and M139 CCA cells after treatment with $\mathrm{XN}$, whereas BAX protein expression was increased (Fig. 3).

Antitumor activity of XN in CCA inoculated mice. To evaluate an in vivo anticancer activity of XN, KKU-M214 CCA cells were subcutaneously inoculated into athymic BALB/c nude mice, then the mice were administrated with $0.5 \%$ 
A

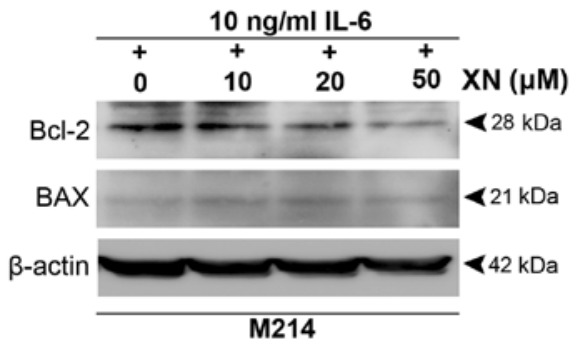

B

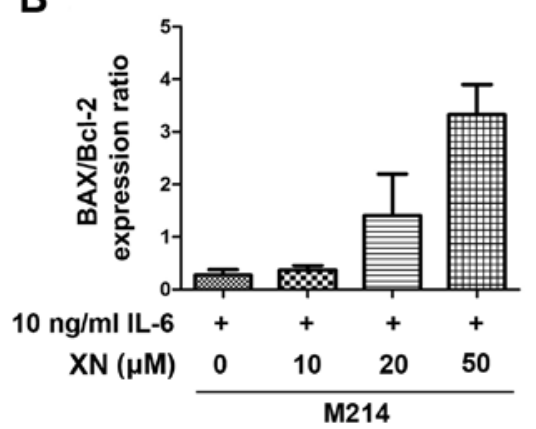

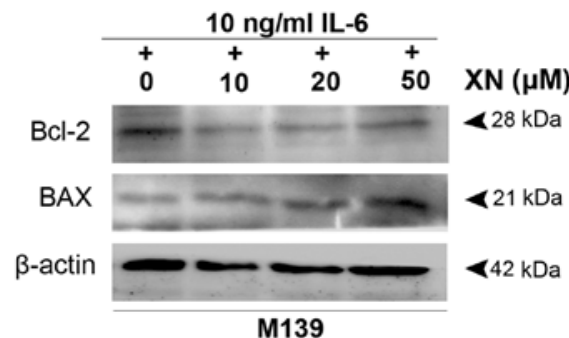

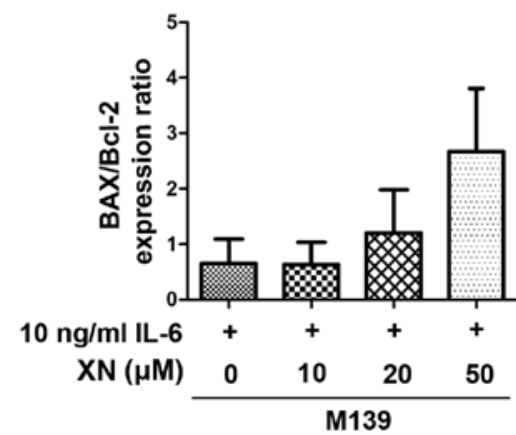

Figure 3. Effects of XN on apoptosis induction of CCA cell lines. (A) Western blot analysis showed apoptotic protein expression in CCA cell lines after treatment with $\mathrm{XN}$ and (B) BAX/Bcl-2 protein expression ratio. Data in B are mean \pm SD of protein band intensity which were normalized to intensity of $\beta$-actin from two independent experiments.

ethanol (as control) or 20 and $50 \mu \mathrm{M}$ concentrations of $\mathrm{XN}$ in drinking water for 30 days and tumor growth was determined. The results showed that $50 \mu \mathrm{M}$ concentrations of XN significantly suppressed the rate of tumor growth when compared with control mice at day 23 (Fig. 4A). A $20 \mu \mathrm{M}$ concentration of $\mathrm{XN}$, however, had no effect on the inhibition of tumor growth (Fig. 4A). No side-effects were observed during the treatment. Histological features of internal organs including liver, spleen and kidney indicated an absence of toxicity (data not shown). Mice treated with XN had similar body weight and water intake rate as the control mice (Fig. 4B and C).

XN inhibits STAT3 activation and tumor cell proliferation, but induces apoptosis in the CCA mouse model. As shown in the in vitro results, we found that XN can inhibit STAT3 activation as well as CCA cell growth and survival. Moreover, the inhibitory growth effect of XN was observed for XN $50 \mu \mathrm{M}$ concentrations in treated CCA xenograft. Thus, we investigated whether the observed effects were due to an inhibitory effect of XN on STAT3 activation. We demonstrated that STAT3 activation was reduced in tumor tissues of XN $50 \mu \mathrm{M}$ concentrations in treated mice when compared to control mice (Fig. 5A). The effects of XN on tumor cell proliferation inhibition and apoptosis induction were further evaluated. Immunostaining of Ki67 proliferation marker was performed to confirm antiproliferation activity of XN (Fig. 5B). Ki67 nuclei stained tumor cells of XN $50 \mu \mathrm{M}$ concentrations treated mice was significantly decreased when compared to control group (Fig. 5C). Moreover, the apoptosis induction activity of $\mathrm{XN}$ was detected by immunohistochemistry of TUNEL (Fig. 5D). Cell apoptosis was significantly higher in $\mathrm{XN}$-treated tumors than in the control group (Fig. 5E).

Molecular mechanisms by which XN inhibits STAT3 activation in $C C A$. The above data revealed an inhibitory effect of $\mathrm{XN}$ on

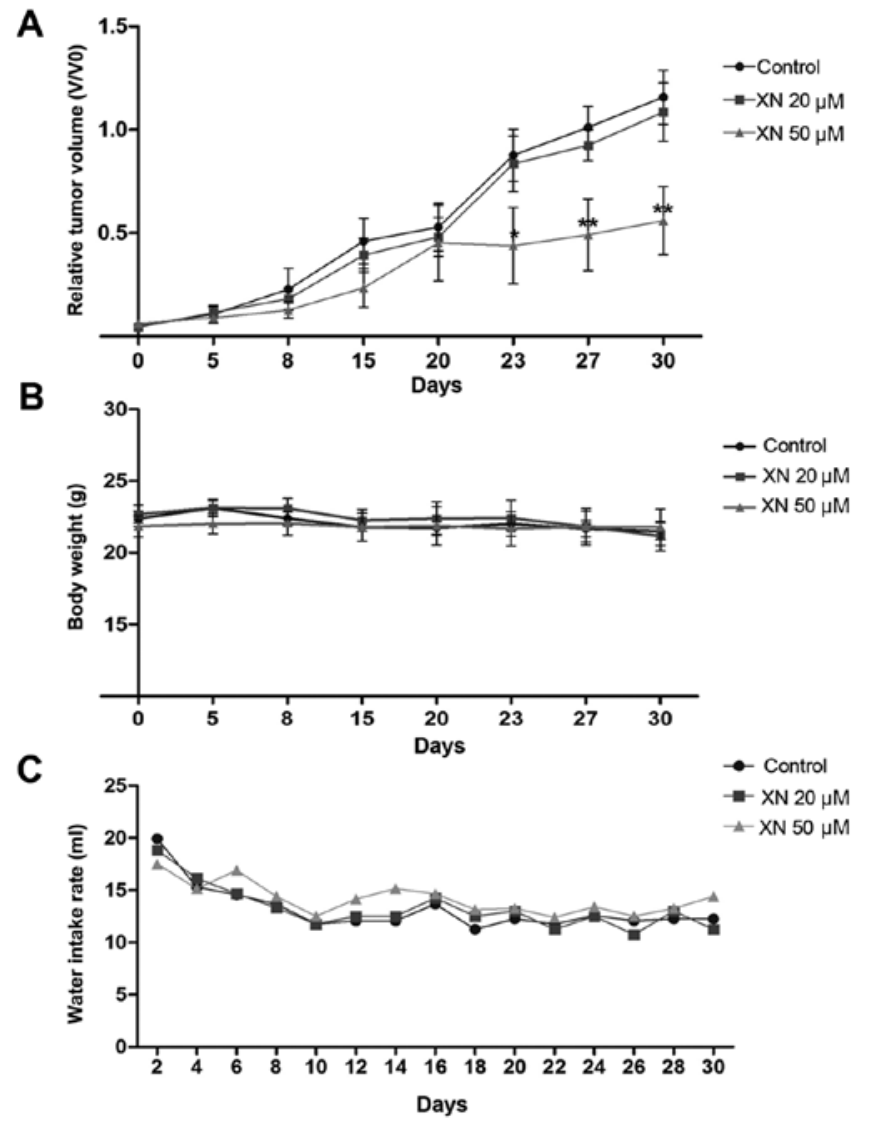

Figure 4. Antitumor activity of XN on CCA-inoculated mice. (A) Tumor growth in mice that received 20 and $50 \mu \mathrm{M}$ concentrations of $\mathrm{XN}$ in drinking water for 30 days were decreased significantly when compared to control mice. (B) The average body weight of mice in each group. (C) Water intake rate of mice in each group along the treatment period. Tumor volume (V) was calculated from $0.5 \mathrm{x}$ length $\mathrm{x}$ width $^{2}$, relative tumor volume $=$ tumor volume $(\mathrm{V}) /$ tumor volume day $0\left(\mathrm{~V}_{0}\right)$. Data in $\mathrm{A}$ and $\mathrm{B}$, are presented as mean \pm SD and analyzed by two-way ANOVA, ${ }^{*} \mathrm{P}<0.05,{ }^{* *} \mathrm{P}<0.001$. Data in $\mathrm{C}$, is addressed as mean volume of water intake. 
A

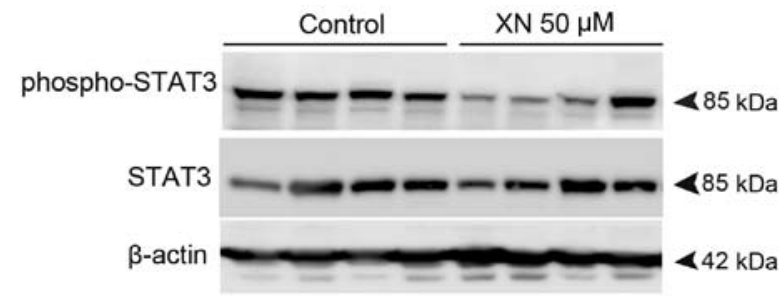

B

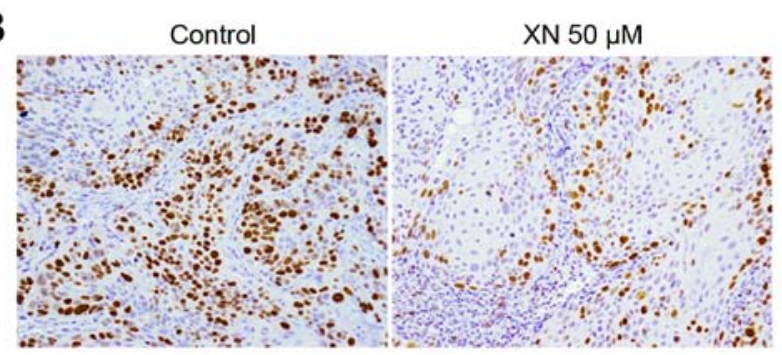

D

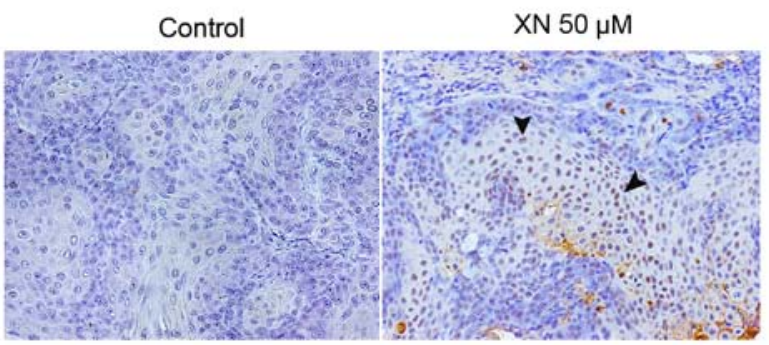

C

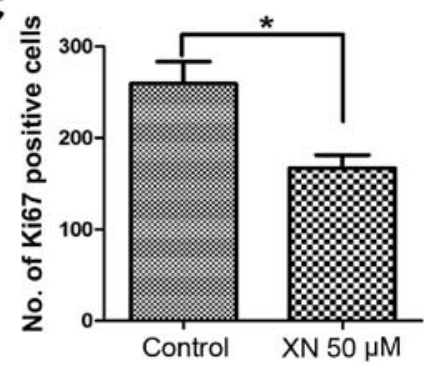

E

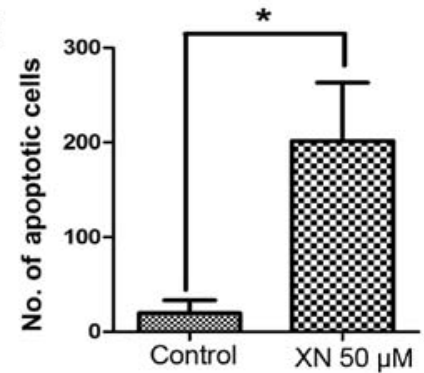

Figure 5. Inhibitory effects of XN on STAT3 activation and tumor development in CCA mouse model. (A) Western blot analysis presents the decrease of STAT3 activation in tumor tissues from XN-treated mice. (B) Proliferative cells were determined by IHC of Ki67 (magnification, x200). (C) The number of proliferative cells was decreased in XN-treated mouse tumor tissues. (D) Apoptotic cells in tumor tissues (arrowheads) which were identified by TUNEL, magnification, $\mathrm{x} 200$. (E) The number of apoptotic cells was increased in $\mathrm{XN}$-treated mouse tumor tissues. Data in $\mathrm{C}$ and $\mathrm{E}$, is the mean $\pm \mathrm{SD}$, $\mathrm{P}<0.05$ analyzed by independent samples t-test.

STAT3 activation both in vitro and in vivo. Thus, we explored the molecular mechanisms by which XN could inhibit STAT3 activation in CCA. We focused on Akt and NFkB signaling as molecular targets of $\mathrm{XN}$ as there is mounting evidence that support the association between Akt, NFkB and STAT3 activation (26-29).

Our results showed that $\mathrm{XN}$ also suppresses Akt activation as well as the nuclear translocation activity of p65 NFKB in both IL-6-induced CCA cells (Fig. 6A and B) and the CCA xenograft model (Fig. 6C and D). This suggests that the mechanisms by which XN suppresses STAT3 activation in CCA resulted from the inhibition of Akt-NFkB signaling.

\section{Discussion}

STAT3 is a protein kinase, which plays various roles as a signal messenger and as a transcription factor. STAT3 signaling can be triggered by inflammatory cytokines, growth factors and hormones, particularly IL-6 $(8,9)$. Stat 3 knockout mice and tissue-specific gene deletions revealed the critical roles of STAT3 in the regulation of epithelial cell apoptosis, involution in skin remodeling, keratinocyte migration, macrophage inactivation, and reduction of T-helper cell responses to IL-6 (30-32). Thus indicating diverse functions of STAT3 both in the immune response and cellular development.
Conversely, sustained activation of STAT3 is implicated in malignant transformation. Various studies have demonstrated that constitutive STAT3 signaling was required for oncogenic transformation (33-35). In CCA, several studies have investigated whether STAT3 acts as a critical molecule in carcinogenesis and progression of CCA (11,36-38).

Our previous study showed that the activation of the STAT protein family occurred in both CCA cells and tissues (13). Moreover, we demonstrated that among the members of the STAT protein, STAT3 expression was associated with shorter survival of CCA patients as well as prominently activating chronic inflammatory CCA carcinogenesis in a hamster model and CCA cell lines (15). Furthermore, we showed that LPS-induced macrophage conditioned media, which contains several inflammatory cytokines including IL-6 (39), can mediate STAT3 activation in CCA cells (15). Hence, STAT3 is the major STAT that is involved in inflammation contributing to CCA carcinogenesis and progression, and may serve as a molecular marker for CCA poor prognosis. Therefore, targeting STAT3 could be beneficial for CCA prevention and treatment. In the present study, we aimed to inhibit STAT3 activation using a potential anti-inflammatory agent, xanthohumol $(\mathrm{XN})$ in order to evaluate whether STAT3 could be a promising target for $\mathrm{XN}$ resulting in the inhibition of CCA growth. 

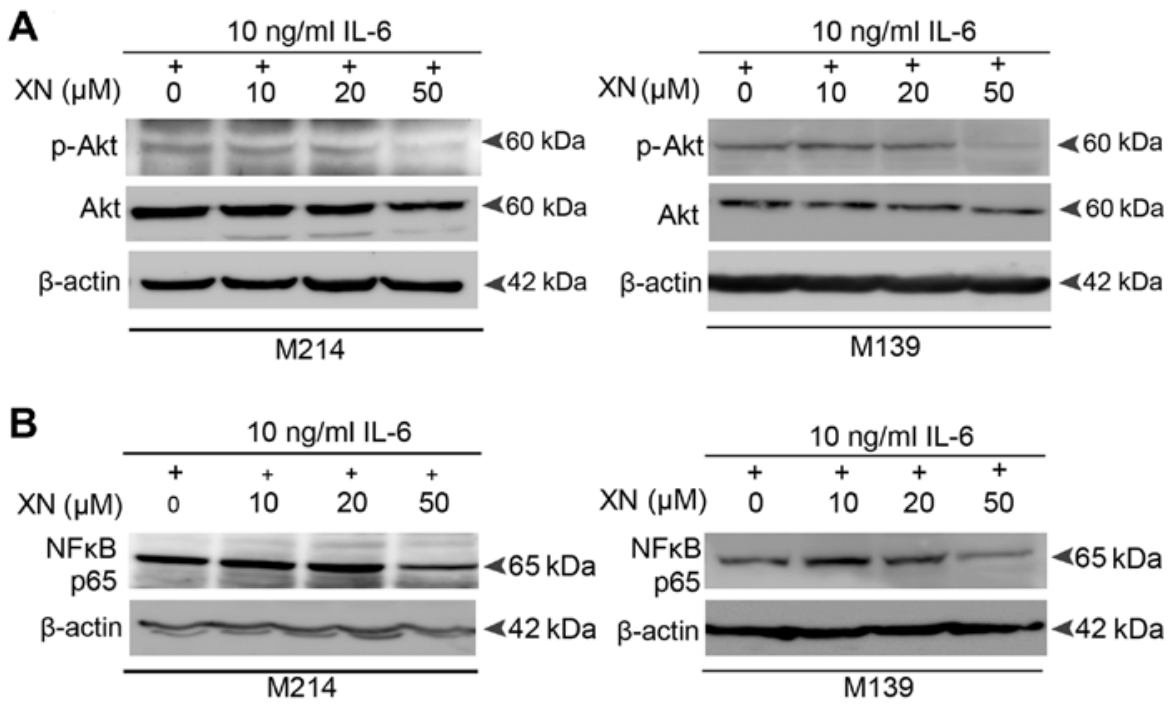

C
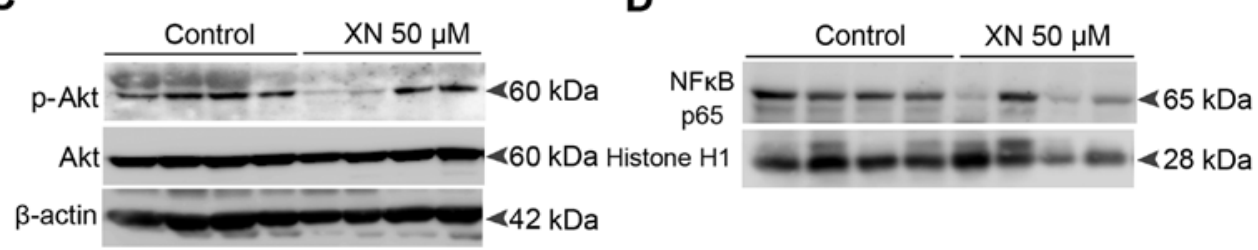

Figure 6. Molecular mechanisms by which XN inhibits STAT3 activation in CCA. (A) Western blot results represent the decreased Akt activation in IL-6induced CCA cell lines after treatment with XN. (B) The decreased p65 NFאB nuclear translocation activity in IL-6-induced CCA cells after treatment with $50 \mu \mathrm{M}$ concentration of $\mathrm{XN}$. (C) $\mathrm{XN}$ inhibits Akt activation in CCA inoculated mice. (D) The decrease of p65 NFkB nuclear translocation activity in CCA inoculated mice.

$\mathrm{XN}$, prenylated chalcone which can be isolated from the hop plant (Humulus lupulus L.), has been identified and reported as an anti-inflammatory and chemopreventive agent $(20,40)$. XN provides anti-inflammation and antitumor potential by interfering with molecules which are recognized as key mediators in inflammation associated carcinogenesis and progression including iNOS, COX2, NFкB and Akt. Previous studies on Kaposi's sarcoma, hematopoietic cancer, prostate cancer, and breast cancer, have demonstrated apoptosis induction and an anti-angiogenic effect of $\mathrm{XN}$ through $\mathrm{Akt}$ and $\mathrm{NF \kappa B}$ signaling inhibition $(21,22,24,41,42)$. Recently, we demonstrated the inhibitory effect of XN on COX activity which leads to decreased PGE2 production as well as CCA cell migration inhibition (43), suggesting a potential chemopreventive and anticancer activity of $\mathrm{XN}$ against cancers including CCA.

The present study showed that XN can inhibit CCA cell proliferation in a dose- and time-dependent manner. Moreover, this is the first time that an inhibitory effect of XN on STAT3 activation has been demonstrated. We revealed that XN at $20 \mu \mathrm{M}$ concentration could partially suppress IL-6-induced STAT3 activation in CCA cells and a complete inhibitory effect was seen at $50 \mu \mathrm{M}$ concentration. In addition, our results revealed that inhibition of STAT3 activation by XN was associated with not only growth inhibition but also apoptosis induction of CCA cells. Abrogation of STAT3 activation by XN caused significant reduction of CCA cell growth and concurrently suppressed the expression of the growth-related gene, cyclin D1, which is a specific target gene of STAT3 (44) as well as CDK4, its partner protein. We also found that suppression of STAT3 activation by XN was correlated with CCA cell apoptosis as indicated by downregulation of the antiapoptotic protein Bcl-2, which is a STAT3 target gene (45) while increasing of the pro-apoptotic protein expression BAX was seen.

Based on the in vitro results, we next investigated the inhibitory effects of XN on STAT3 activation and CCA development in a nude mouse model. Our results showed that oral administration of $\mathrm{XN}$ at $50 \mu \mathrm{M}$ concentrations to CCA-inoculated mice attenuated tumor growth without noticeable toxicity. Conversely, a $20 \mu \mathrm{M} \mathrm{XN}$ concentration had no effect on tumor growth suppression. This result was similar to in vitro results which showed that low concentrations of $\mathrm{XN}$ $(2.5,5$ and $10 \mu \mathrm{M})$ cannot inhibit CCA cell growth, however, it induced CCA cell growth as well as STAT3 activation when compared to control group. This may result from the compensatory signaling mechanisms of cancer cells that can overcome an inhibitory effect of low concentration of XN which can lead to an increase of STAT3 activation as well as tumor proliferation. This phenomenon can be explained by the acquired resistance mechanism of cancer when blocked by inhibitor treatment. When signaling is inhibited by the inhibitor, the signaling loop is disrupted which causes upregulation or increased activation of target molecules that mediate signaling redundancy, which is the compensatory signaling mechanism in cancer treatment (46).

Our in vivo results showed that tumor tissues from $\mathrm{XN}$-treated mice exhibited reduced STAT3 activation as well as suppressed tumor proliferation and increased apoptosis 
induction. These findings suggest that STAT3 is a promising target of $\mathrm{XN}$ and reveal, antitumor activity of $\mathrm{XN}$ against $\mathrm{CCA}$ growth and survival.

Furthermore, we explored the molecular mechanisms by which XN inhibits STAT3 activation in CCA. Results showed that $\mathrm{XN}$ provided anticancer activities via the suppression of Akt and $\mathrm{NF \kappa B}$, the molecules that are involved in the proliferation, survival and angiogenesis of tumor cells. Moreover, the interconnection between Akt-NFkB and STAT3 signaling has been described (26-29). Our results showed a decreased activation of Akt and $\mathrm{NF \kappa B}$ after treatment with $\mathrm{XN}$ in both the IL-6-induced CCA cells and the CCA inoculated mice. Therefore, the possible mechanisms by which XN suppresses STAT3 activation in CCA could be due to Akt-NFאB signaling inhibition.

In conclusion, we have shown that XN can inhibit STAT3 activation in human CCA cell lines as well as CCA inoculated mice. Moreover, XN can effectively suppress the growth of tumor and induce apoptosis in CCA cells and tumor inoculated mice without any noticeable side-effects. This is the first time that STAT3 has been demonstrated as a potential target of $\mathrm{XN}$. Moreover, our results have shown the potential efficacy of $\mathrm{XN}$ for CCA treatment. The above knowledge can provide the basis to develop new therapeutic strategies for CCA using XN alone and/or combined with conventional chemotherapy drugs to improve the efficacy of CCA treatment.

\section{Acknowledgements}

We thank the research technicians (Division of Molecular Pathology, Department of Cancer Biology, Institute of Medical Science, The University of Tokyo) who kindly assisted us in the animal experiment. The present study was supported by Liver Fluke and Cholangiocarcinoma Research Center to H.D., the Research Assistantship Grant of the Faculty of Medicine, Khon Kaen University (grant no. AS57202) and the Khon Kaen University Grant (KKU59), the co-funding from Japan Science and Technology Agency (JST), Ministry of Education, Culture, Sport, Science and Technology of Japan, and grant of the Higher Education Research Promotion and National Research University Project of Thailand, Office of the Higher Education Commission, through the Center of Excellence in Specific Health Problems in Greater Mekong Sub-region cluster (SHeP-GMS), KhonKaen University. We also thank Professor Ross H. Andrews for editing the initial submission via Publication Clinic KKU, Thailand.

\section{References}

1. Elkins DB, Haswell-Elkins MR, Mairiang E, Mairiang $P$ Sithithaworn P, Kaewkes S, Bhudhisawasdi V and Uttaravichien T: A high frequency of hepatobiliary disease and suspected cholangiocarcinoma associated with heavy Opisthorchis viverrini infection in a small community in north-east Thailand. Trans $\mathrm{R}$ Soc Trop Med Hyg 84: 715-719, 1990.

2. Elkins DB, Mairiang E, Sithithaworn P, Mairiang P, Chaiyakum J, Chamadol N, Loapaiboon V and Haswell-Elkins MR: Crosssectional patterns of hepatobiliary abnormalities and possible precursor conditions of cholangiocarcinoma associated with Opisthorchis viverrini infection in humans. Am J Trop Med Hyg 55: 295-301, 1996.

3. Sripa B and Pairojkul C: Cholangiocarcinoma: Lessons from Thailand. Curr Opin Gastroenterol 24: 349-356, 2008.
4. Khan SA, Thomas HC, Davidson BR and Taylor-Robinson SD: Cholangiocarcinoma. Lancet 366: 1303-1314, 2005.

5. Shaib Y and El-Serag HB: The epidemiology of cholangiocarcinoma. Semin Liver Dis 24: 115-125, 2004.

6. Khan SA, Taylor-Robinson SD, Toledano MB, Beck A, Elliott P and Thomas HC: Changing international trends in mortality rates for liver, biliary and pancreatic tumours. J Hepatol 37: 806-813, 2002.

7. Khuntikeo N, Pugkhem A, Titapun A and Bhudhisawasdi V: Surgical management of perihilar cholangiocarcinoma: A Khon Kaen experience. J Hepatobiliary Pancreat Sci 21: 521-524, 2014.

8. Ihle JN: The Stat family in cytokine signaling. Curr Opin Cell Biol 13: 211-217, 2001

9. Takeda K and Akira S: STAT family of transcription factors in cytokine-mediated biological responses. Cytokine Growth Factor Rev 11: 199-207, 2000.

10. Bromberg J: Stat proteins and oncogenesis. J Clin Invest 109: 1139-1142, 2002.

11. Smirnova OV, Ostroukhova TY and Bogorad RL: JAK-STAT pathway in carcinogenesis: Is it relevant to cholangiocarcinoma progression? World J Gastroenterol 13: 6478-6491, 2007.

12. Yu H, Pardoll D and Jove R: STATs in cancer inflammation and immunity: A leading role for STAT3. Nat Rev Cancer 9: 798-809, 2009.

13. Dokduang H, Juntana S, Techasen A, Namwat N, Yongvanit P, Khuntikeo N, Riggins GJ and Loilome W: Survey of activated kinase proteins reveals potential targets for cholangiocarcinoma treatment. Tumour Biol 34: 3519-3528, 2013.

14. Loilome W, Juntana S, Namwat N, Bhudhisawasdi V, Puapairoj A, Sripa B, Miwa M, Saya H, Riggins GJ and Yongvanit P: PRKAR1A is overexpressed and represents a possible therapeutic target in human cholangiocarcinoma. Int J Cancer 129: 34-44, 2011.

15. Dokduang H, Techasen A, Namwat N, Khuntikeo N, Pairojkul C, Murakami Y, Loilome W and Yongvanit P: STATs profiling reveals predominantly-activated STAT3 in cholangiocarcinoma genesis and progression. J Hepatobiliary Pancreat Sci 21: 767-776, 2014.

16. González-Vallinas M, González-Castejón M, RodríguezCasado A and Ramírez de Molina A: Dietary phytochemicals in cancer prevention and therapy: A complementary approach with promising perspectives. Nutr Rev 71: 585-599, 2013.

17. Landis-Piwowar KR and Iyer NR: Cancer chemoprevention: Current state of the art. Cancer Growth Metastasis 7: 19-25, 2014.

18. Murakami A, Ohigashi $\mathrm{H}$ and Koshimizu K: Anti-tumor promotion with food phytochemicals: A strategy for cancer chemoprevention. Biosci Biotechnol Biochem 60: 1-8, 1996.

19. Surh YJ: Cancer chemoprevention with dietary phytochemicals. Nat Rev Cancer 3: 768-780, 2003.

20. Gerhauser C, Alt A, Heiss E, Gamal-Eldeen A, Klimo K, Knauft J, Neumann I, Scherf HR, Frank N, Bartsch H, et al: Cancer chemopreventive activity of Xanthohumol, a natural product derived from hop. Mol Cancer Ther 1: 959-969, 2002.

21. Albini A, Dell Eva R, Vené R, Ferrari N, Buhler DR, Noonan DM and Fassina G: Mechanisms of the antiangiogenic activity by the hop flavonoid xanthohumol: NF-kappaB and Akt as targets. FASEB J 20: 527-529, 2006.

22. Dell'Eva R, Ambrosini C, Vannini N, Piaggio G, Albini A and Ferrari N: AKT/NF-kappaB inhibitor xanthohumol targets cell growth and angiogenesis in hematologic malignancies. Cancer 110: 2007-2011, 2007.

23. Harikumar KB, Kunnumakkara AB, Ahn KS, Anand P, Krishnan S, Guha S and Aggarwal BB: Modification of the cysteine residues in IkappaBalpha kinase and NF-kappaB (p65) by xanthohumol leads to suppression of NF-kappaB-regulated gene products and potentiation of apoptosis in leukemia cells. Blood 113: 2003-2013, 2009.

24. Monteghirfo S, Tosetti F, Ambrosini C, Stigliani S, Pozzi S, Frassoni F, Fassina G, Soverini S, Albini A and Ferrari N: Antileukemia effects of xanthohumol in Bcr/Abl-transformed cells involve nuclear factor-kappaB and p53 modulation. Mol Cancer Ther 7: 2692-2702, 2008.

25. Namwat N, Amimanan P, Loilome W, Jearanaikoon P, Sripa B, Bhudhisawasdi V and Tassaneeyakul W: Characterization of 5-fluorouracil-resistant cholangiocarcinoma cell lines. Chemotherapy 54: 343-351, 2008.

26. Blando JM, Carbajal S, Abel E, Beltran L, Conti C, Fischer S and DiGiovanni J: Cooperation between Stat 3 and Akt signaling leads to prostate tumor development in transgenic mice. Neoplasia 13: 254-265, 2011. 
27. Kortylewski M, Feld F, Krüger KD, Bahrenberg G, Roth RA, Joost HG, Heinrich PC, Behrmann I and Barthel A: Akt modulates STAT3-mediated gene expression through a FKHR (FOXO1a)-dependent mechanism. J Biol Chem 278: 5242-5249, 2003.

28. Squarize CH, Castilho RM, Sriuranpong V, Pinto DS Jr and Gutkind JS: Molecular cross-talk between the NFkappaB and STAT3 signaling pathways in head and neck squamous cell carcinoma. Neoplasia 8: 733-746, 2006.

29. Zhou J, Wulfkuhle J, Zhang H, Gu P, Yang Y, Deng J, Margolick JB, Liotta LA, Petricoin E III and Zhang Y: Activation of the PTEN/mTOR/STAT3 pathway in breast cancer stem-like cells is required for viability and maintenance. Proc Natl Acad Sci USA 104: 16158-16163, 2007.

30. Sano S, Itami S, Takeda K, Tarutani M, Yamaguchi Y, Miura H, Yoshikawa K, Akira S and Takeda J: Keratinocyte-specific ablation of Stat 3 exhibits impaired skin remodeling, but does not affect skin morphogenesis. EMBO J 18: 4657-4668, 1999.

31. Takeda K, Clausen BE, Kaisho T, Tsujimura T, Terada N Förster I and Akira S: Enhanced Th1 activity and development of chronic enterocolitis in mice devoid of Stat3 in macrophages and neutrophils. Immunity 10: 39-49, 1999.

32. Takeda K, Noguchi K, Shi W, Tanaka T, Matsumoto M, Yoshida N, Kishimoto T and Akira S: Targeted disruption of the mouse Stat3 gene leads to early embryonic lethality. Proc Natl Acad Sci USA 94: 3801-3804, 1997.

33. Bromberg JF, Horvath CM, Besser D, Lathem WW and Darnell JE Jr: Stat3 activation is required for cellular transformation by v-src. Mol Cell Biol 18: 2553-2558, 1998.

34. Cao X, Tay A, Guy GR and Tan YH: Activation and association of Stat 3 with Src in v-Src-transformed cell lines. Mol Cell Biol 16: 1595-1603, 1996.

35. Turkson J, Bowman T, Garcia R, Caldenhoven E, De Groot RP and Jove R: Stat3 activation by Src induces specific gene regulation and is required for cell transformation. Mol Cell Biol 18 2545-2552, 1998.

36. Isomoto H, Mott JL, Kobayashi S, Werneburg NW, Bronk SF, Haan S and Gores GJ: Sustained IL-6/STAT-3 signaling in cholangiocarcinoma cells due to SOCS-3 epigenetic silencing. Gastroenterology 132: 384-396, 2007.
37. Sia D, Hoshida Y, Villanueva A, Roayaie S, Ferrer J, Tabak B, Peix J, Sole M, Tovar V, Alsinet C, et al: Integrative molecular analysis of intrahepatic cholangiocarcinoma reveals 2 classes that have different outcomes. Gastroenterology 144: 829-840, 2013.

38. Sia D, Tovar V, Moeini A and Llovet JM: Intrahepatic cholangiocarcinoma: Pathogenesis and rationale for molecular therapies. Oncogene 32: 4861-4870, 2013.

39. Techasen A, Loilome W, Namwat N, Dokduang H, Jongthawin J and Yongvanit P: Cytokines released from activated human macrophages induce epithelial mesenchymal transition markers of cholangiocarcinoma cells. Asian Pac J Cancer Prev 13 (Suppl): S115-S118, 2012

40. Gerhäuser C: Beer constituents as potential cancer chemopreventive agents. Eur J Cancer 41: 1941-1954, 2005.

41. Colgate EC, Miranda CL, Stevens JF, Bray TM and Ho E: Xanthohumol, a prenylflavonoid derived from hops induces apoptosis and inhibits NF-kappaB activation in prostate epithelial cells. Cancer Lett 246: 201-209, 2007.

42. Monteiro R, Calhau C, Silva AO, Pinheiro-Silva S, Guerreiro S, Gärtner F, Azevedo I and Soares R: Xanthohumol inhibits inflammatory factor production and angiogenesis in breast cancer xenografts. J Cell Biochem 104: 1699-1707, 2008.

43. Jongthawin J, Techasen A, Loilome W, Yongvanit P and Namwat N: Anti-inflammatory agents suppress the prostaglandin E2 production and migration ability of cholangiocarcinoma cell lines. Asian Pac J Cancer Prev 13 (Suppl): 47-51, 2012.

44. Liu B, Ren Z, Shi Y, Guan C, Pan Z and Zong Z: Activation of signal transducers and activators of transcription 3 and overexpression of its target gene CyclinD1 in laryngeal carcinomas. Laryngoscope 118: 1976-1980, 2008.

45. Williams JG: STAT signalling in cell proliferation and in development. Curr Opin Genet Dev 10: 503-507, 2000.

46. Logue JS and Morrison DK: Complexity in the signaling network: Insights from the use of targeted inhibitors in cancer therapy. Genes Dev 26: 641-650, 2012. 